\title{
High Body Mass Index and Central Adiposity Is Associated with Increased Risk of Acute Pancreatitis: A Meta-Analysis
}

\author{
Dagfinn Aune ${ }^{1,2,3}$ (D) $\cdot$ Yahya Mahamat-Saleh ${ }^{4,5} \cdot$ Teresa Norat $^{1} \cdot$ Elio Riboli $^{1}$
}

Received: 13 April 2019 / Accepted: 16 April 2020 / Published online: 19 June 2020

(C) The Author(s) 2020

\begin{abstract}
Background Higher body mass index and waist circumference have been associated with increased risk of pancreatitis in several prospective studies; however, the results have not been entirely consistent.

Aims We conducted a systematic review and dose-response meta-analysis of prospective studies on adiposity and risk of pancreatitis to clarify this association.

Methods PubMed and Embase databases were searched for studies on adiposity and pancreatitis up to January 27, 2020. Prospective studies reporting adjusted relative risk (RR) estimates and 95\% confidence intervals (CIs) for the association between adiposity and risk of pancreatitis were included, and summary RRs (95\% CIs) were calculated using a random effects model.

Results Ten prospective studies with 5129 cases and 1,693,657 participants were included. The summary RR (95\% CI) of acute pancreatitis was 1.18 (95\% CI: $1.03-1.35, I^{2}=91 \%, n=10$ studies) per $5 \mathrm{~kg} / \mathrm{m}^{2}$ increase in BMI and 1.36 (95\% CI: $\left.1.29-1.43, I^{2}=0 \%, n=3\right)$ per $10 \mathrm{~cm}$ increase in waist circumference. There was evidence of a nonlinear association between BMI and acute pancreatitis, $p_{\text {nonlinearity }}<0.0001$, with a steeper association at higher levels of BMI, but not for waist circumference, $p_{\text {nonlinearity }}=0.19$. Comparing a BMI of 35 with a BMI of 22 , there was a $58 \%$ increase in the RR and there was a fourfold increase in the RR comparing a waist circumference of $110 \mathrm{~cm}$ with $69 \mathrm{~cm}$. There was no evidence of publication bias. Conclusions This meta-analysis suggests that both increasing BMI and waist circumference are associated with a doseresponse-related increase in the risk of acute pancreatitis.
\end{abstract}

Keywords Body mass index $\cdot$ Central adiposity $\cdot$ Waist circumference $\cdot$ Pancreatitis $\cdot$ Systematic review $\cdot$ Meta-analysis

Electronic supplementary material The online version of this article (https://doi.org/10.1007/s10620-020-06275-6) contains supplementary material, which is available to authorized users.

Dagfinn Aune

d.aune@imperial.ac.uk

Yahya Mahamat-Saleh

Yahya.MAHAMAT-SALEH@gustaveroussy.fr

Teresa Norat

t.norat@imperial.ac.uk

Elio Riboli

e.riboli@imperial.ac.uk

1 Department of Epidemiology and Biostatistics, School of Public Health, Imperial College London, St. Mary's Campus, Norfolk Place, Paddington, London W2 1PG, UK

\section{Introduction}

Pancreatitis is an inflammatory disorder of the pancreas characterized by symptoms such as severe abdominal pain, nausea and vomiting [1]. Pancreatitis develops when digestive enzymes produced by the pancreas are activated in the

2 Department of Nutrition, Bjørknes University College, Oslo, Norway

3 Department of Endocrinology, Morbid Obesity and Preventive Medicine, Oslo University Hospital, Oslo, Norway

4 CESP, Fac. de médecine, Univ. Paris-Sud, Fac. de médecine, INSERM (French National Institute for Health and Medical Research), Université Paris-Saclay, UVSQ, 94805 Villejuif, France

5 Gustave Roussy, 94805 Villejuif, France 
pancreas instead of in the small intestine, causing inflammation and fibrosis [2]. Pancreatitis is an important risk factor for pancreatic cancer (relative risk of 8) [3, 4] as well as for all-cause and cause-specific mortality [4, 5]. Incidence rates of pancreatitis vary from 4 up to $>100$ cases per 100,000 persons per year globally, with higher rates in America for acute pancreatitis, and in Europe for chronic pancreatitis, while the lowest rates are observed in Southeast Asia [6]. In addition, the incidence of the disease has been increasing substantially over the last decades in secular trend studies in the USA and Europe [7-13]. The wide variation in the incidence of pancreatitis internationally combined with the rapid changes in the incidence of the disease over time within countries suggests that modifiable risk factors may be of major importance in the etiology of the disease. High alcohol intake [4, 14], smoking [4, 15], diabetes mellitus [4] and a history of gallstones $[4,14]$ are among the established or suspected risk factors for pancreatitis.

Overweight and obesity as measured by body mass index (BMI, $\mathrm{kg} / \mathrm{m}^{2}$ ) is an established risk factor for type 2 diabetes [16] and gallstone or gallbladder disease [17], which are risk factors for pancreatitis [4], and adiposity is also an established risk factor for pancreatic cancer [18], for which pancreatitis is a risk factor [4]. High BMI has also been directly associated with increased risk of acute pancreatitis in some prospective studies [4, 19-21]; however, the results are not entirely consistent as several other studies found no clear association [22-24] and one study suggested a U-shaped association [25]. In addition, higher waist circumference has been consistently associated with increased risk of acute pancreatitis $[4,24]$. Whether the association differs by subtype of pancreatitis (e.g., gallstone-related or alcoholrelated pancreatitis) is not clear, and whether the association between BMI and pancreatitis is independent of diabetes or gallbladder disease is also not clear. Two Swedish studies [24] and a Chinese study [4] suggested a stronger association between waist circumference and pancreatitis than for BMI, particularly when mutually adjusted, and this finding might suggest insulin resistance may be an important contributor to pancreatitis. Although two previous meta-analyses found a $34-43 \%$ increase in risk of pancreatitis or acute pancreatitis with obesity [26, 27], they both had several limitations including the low number of studies $(n=5$ and $n=2)$ which led to the combination of patient-based studies (type 2 diabetes, hypertension), one study on recurrent pancreatitis among pancreatitis patients, one case-control study and a population-based cohort study in one meta-analysis [26], while only two cohort studies were included in a second meta-analysis [27]. In addition, no results were reported for overweight and no dose-response analyses were conducted; thus, it is not clear if there is a dose-response relationship between increasing adiposity and pancreatitis or if there are any threshold levels. Given that several population-based cohort studies on adiposity and the risk of incident pancreatitis now have been published [4, 19-25], we therefore conducted a systematic review and dose-response metaanalysis of the available prospective studies to better define the strength and shape of the dose-response relationship between adiposity and risk of pancreatitis.

\section{Materials and Methods}

\section{Search Strategy and Inclusion Criteria}

Pubmed and Embase databases were searched for eligible studies up to January 27, 2020, as part of a larger project on risk factors for pancreatitis. The search terms used are provided in the supplementary text. We followed PRISMA criteria for reporting meta-analyses [28]. The reference lists of the identified publications were also searched for further studies.

\section{Study Selection}

We included published retrospective and prospective cohort studies and nested case-control studies within cohorts that reported adjusted relative risk (RR) estimates and 95\% confidence intervals (CIs) for the association between any measure of adiposity (BMI, waist circumference, waist-tohip ratio, weight gain, body fat) and the risk of pancreatitis. A list of the excluded studies and the exclusion reasons can be found in Supplementary Table 1. DA and YMS conducted the screening of the literature search.

\section{Data Extraction}

The following data were extracted from each study: The first author's last name, publication year, country where the study was conducted, the name of the study, study period and duration of follow-up, sample size, sex, number of cases, measure of adiposity, subgroup, RRs and 95\% CIs and variables adjusted for in the analysis. The data extraction was conducted by DA and checked for accuracy by YMS.

\section{Statistical Methods}

Random effects models were used to calculate summary RRs (95\% CIs) of pancreatitis per $5 \mathrm{~kg} / \mathrm{m}^{2}$ increase in BMI and per $10 \mathrm{~cm}$ of waist circumference (the two adiposity measures which had enough studies to be analyzed) [29]. The average of the natural logarithm of the RRs was estimated, and the RR from each study was weighted using random effects weights. We used the method of Greenland and Longnecker to estimate linear trends across categories of BMI and waist circumference [30]. For studies which reported 
adiposity measures by ranges, we estimated the midpoint for each category. When extreme categories were openended, we estimated an upper and lower cutoff value using the width of the adjacent category; however, when the WHO categories of BMI were used we used 18.5 as a lower cutoff if the upper cutoff was $<25$. For studies in which the lowest category was not the reference category, we used the method of Hamling to convert the risk estimates so the lowest category became the reference category. We also conducted sensitivity analyses simply excluding the categories below the reference category. Fractional polynomial models were used to investigate a potential nonlinear association between BMI and waist circumference and risk of pancreatitis [31, 32]. The best-fitting second-order fractional polynomial regression model, defined as the one with the lowest deviance, was determined. A likelihood ratio test was used to assess the difference between the nonlinear and linear models to test for nonlinearity [31].

Heterogeneity between studies was evaluated using $Q$ and $I^{2}$ statistics [33]. $I^{2}$ is a measure of how much of the heterogeneity that is due to between study variation rather than chance. $I^{2}$-values of $25 \%, 50 \%$ and $75 \%$ indicate low, moderate and high heterogeneity, respectively. We conducted main analyses (all studies combined) and stratified by study characteristics such as sex, duration of follow-up, geographic location, number of cases, study quality and by adjustment for confounding factors to investigate potential sources of heterogeneity. Study quality was assessed using the Newcastle Ottawa scale which rates studies according to selection, comparability and outcome assessment with a score range from 0 to 9 [34].

Publication bias was assessed using Egger's test [35] and Begg-Mazumdar's test [36] and by inspection of funnel plots. The statistical analyses were conducted using the software package Stata, version 13.0 software (StataCorp, Texas, USA).

\section{Results}

We identified ten population-based prospective studies (eight publications, nine risk estimates) [4, 19-25] that were included in the meta-analysis of adiposity and risk of pancreatitis risk (Fig. 1, Table 1). Two publications included results from two studies each; the Swedish Mammography Cohort and the Cohort of Swedish Men [24] and the Copenhagen City Heart Study and the Copenhagen General Population Study [21]. Two studies were conducted in women, one in men and seven studies in men and women combined. Six studies were from Europe, two studies were from the USA and two studies were from Asia (Table 1).

Ten prospective studies (eight publications, nine risk estimates) [4, 19-25] with 1,693,657 participants and 5129
10172 records identified in total:

3088 records identified in the PubMed database

7084 records identified in the Embase database

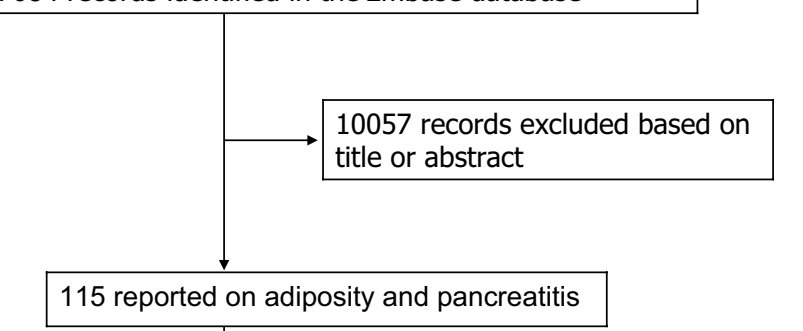

Fig. 1 Flowchart of study selection

cases were included in the analysis of BMI and the risk of acute pancreatitis. The summary RR was 1.18 (95\% CI: $\left.1.03-1.35, I^{2}=91.1 \%, p_{\text {heterogeneity }}<0.0001\right)$ per $5 \mathrm{~kg} / \mathrm{m}^{2}$ increase in BMI (Fig. 2a). There was no evidence of publication bias with Egger's test $(p=0.93)$ or with Begg's test $(p=0.35)$ (Supplementary Figure 1$)$. The summary RR ranged from 1.14 (95\% CI: 1.00-1.30) when excluding the study by Pang et al. [4] to 1.24 (95\% CI: 1.12-1.37) when excluding the study by Choi et al. [25] (Supplementary Figure 2, Supplementary Figure 3a). One large Korean study found a L-shaped or U-shaped association between BMI and pancreatitis, which was more pronounced in ever smokers, and alcohol drinkers than in never smokers and nondrinkers, which could suggest potential residual confounding [25]. When data for never smokers were used instead of the total population for this study, the summary RR was 1.21 (95\% CI: $1.09-1.34, I^{2}=81.5 \%$, $p_{\text {heterogeneity }}<0.0001$ ) per $5 \mathrm{~kg} / \mathrm{m}^{2}$ increase in BMI (Supplementary Figure 4). Alternatively, when excluding the categories below the reference category when the lowest category was not the reference category, the summary RR was 


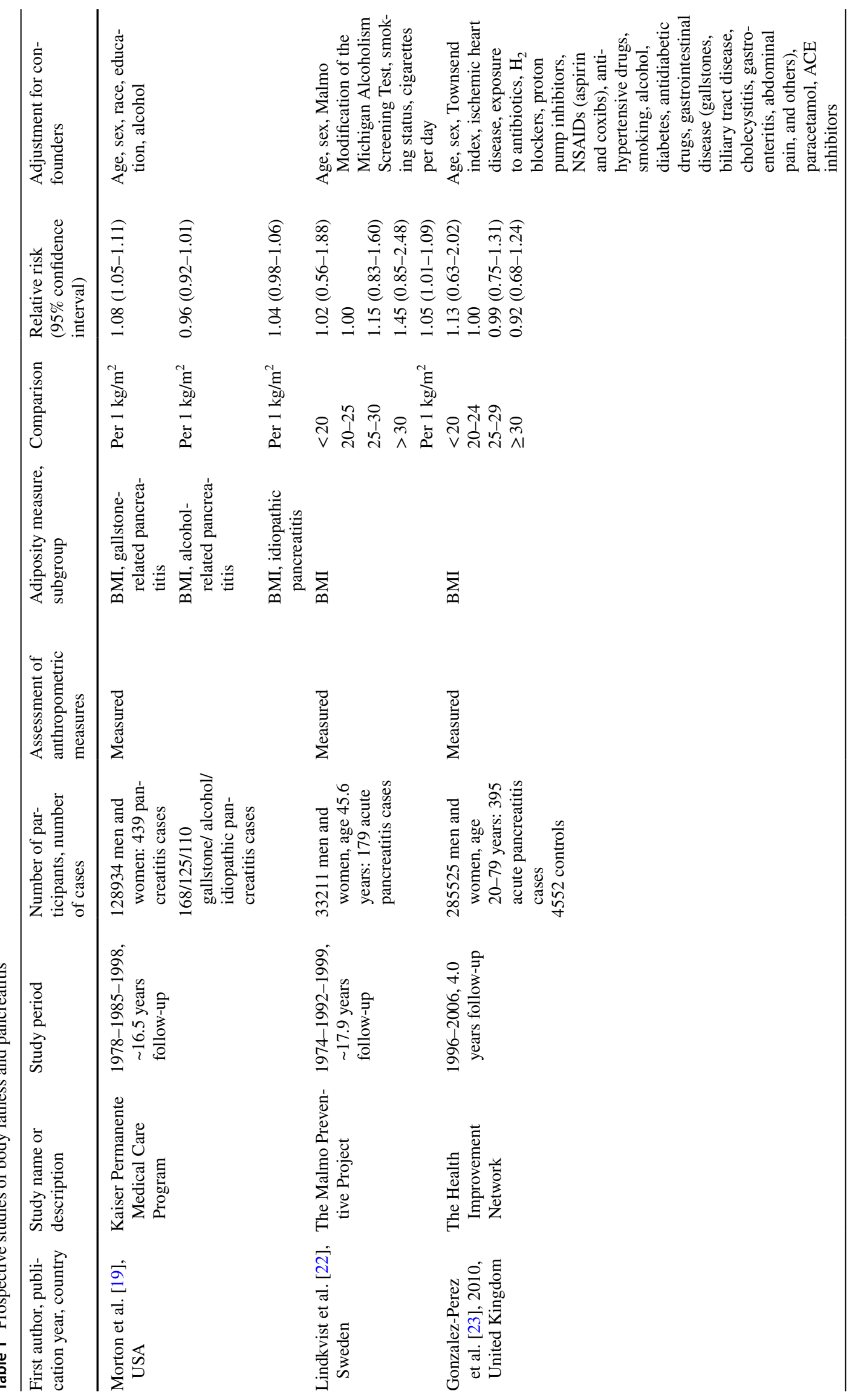




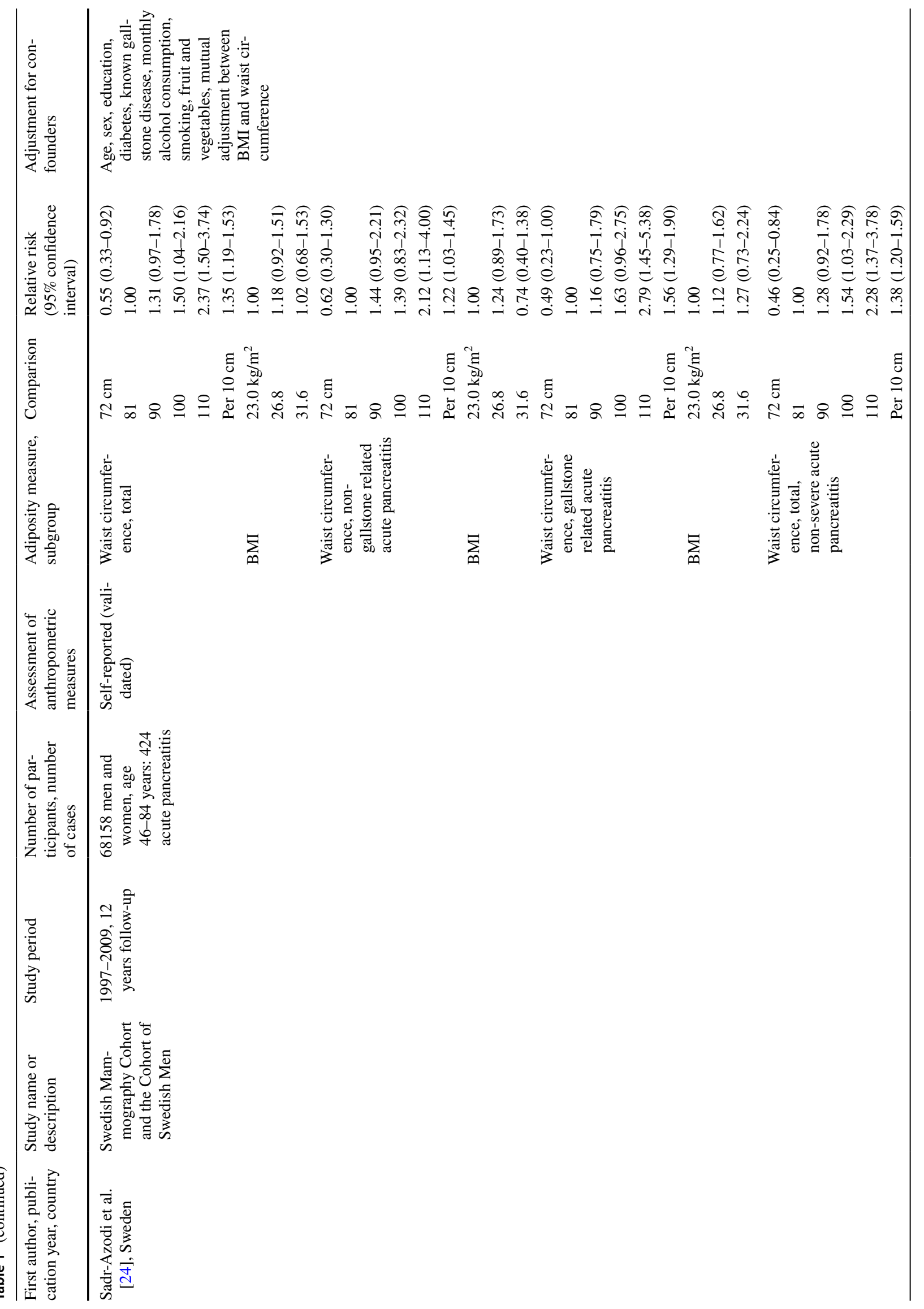




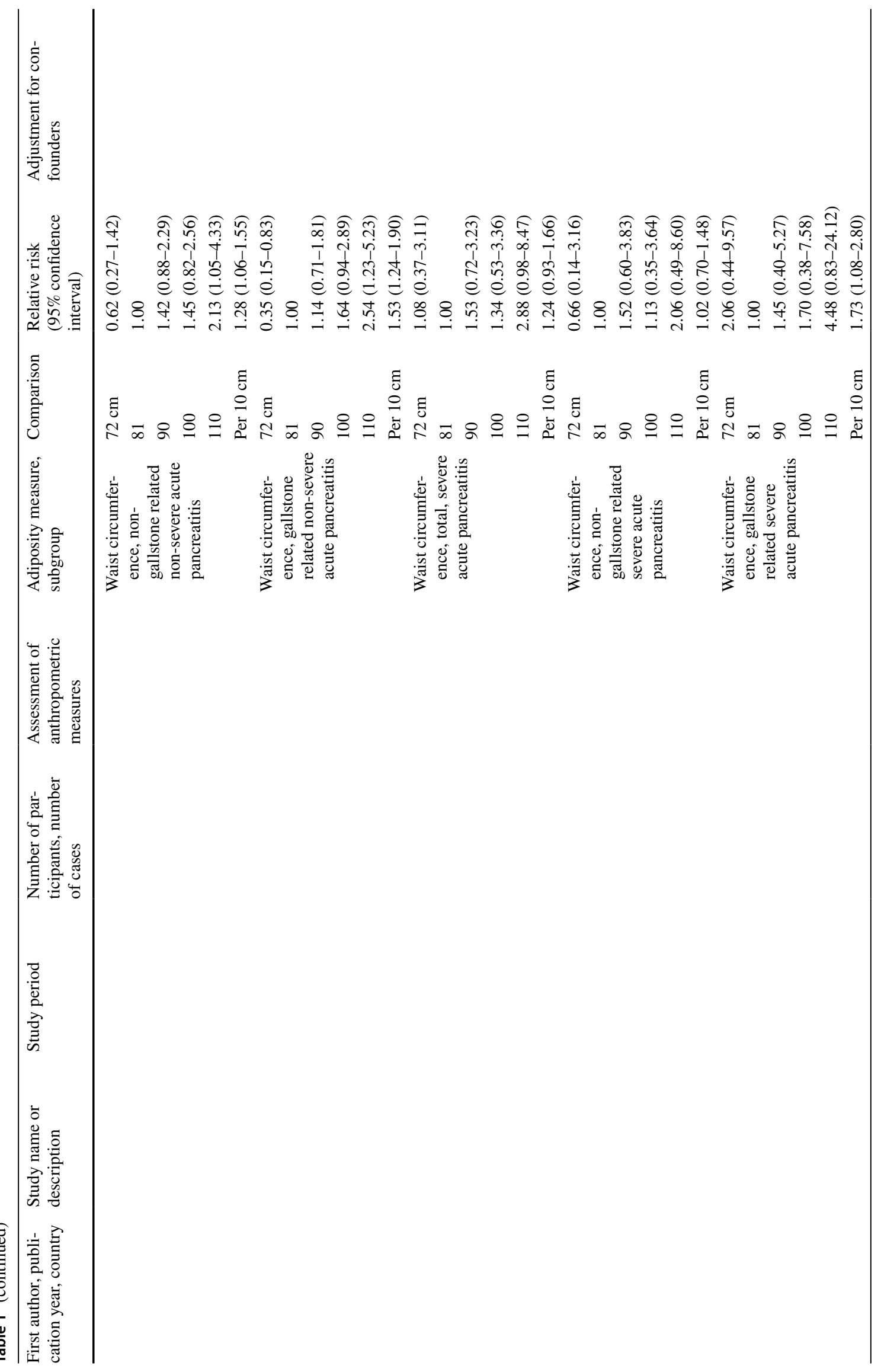




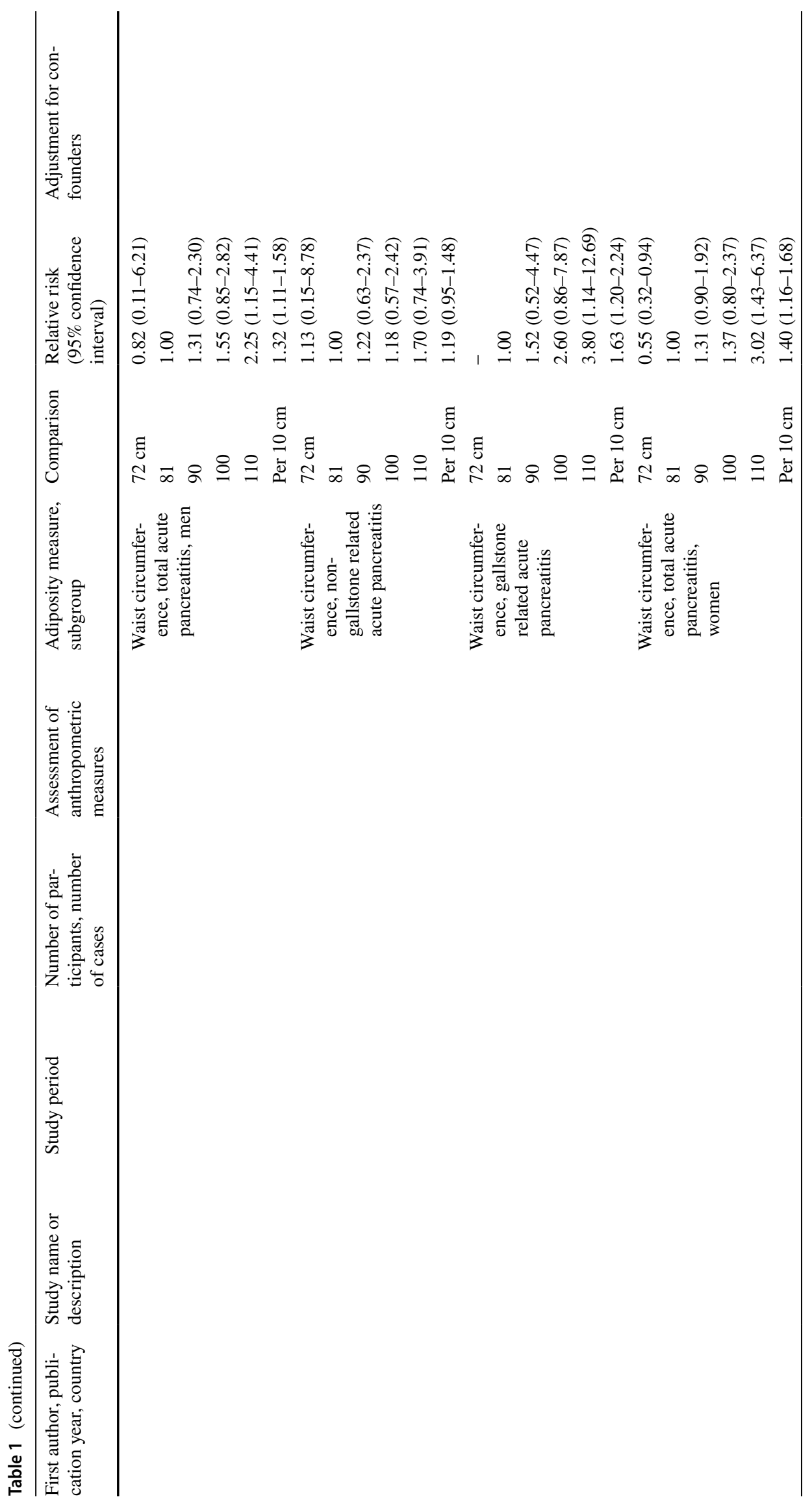




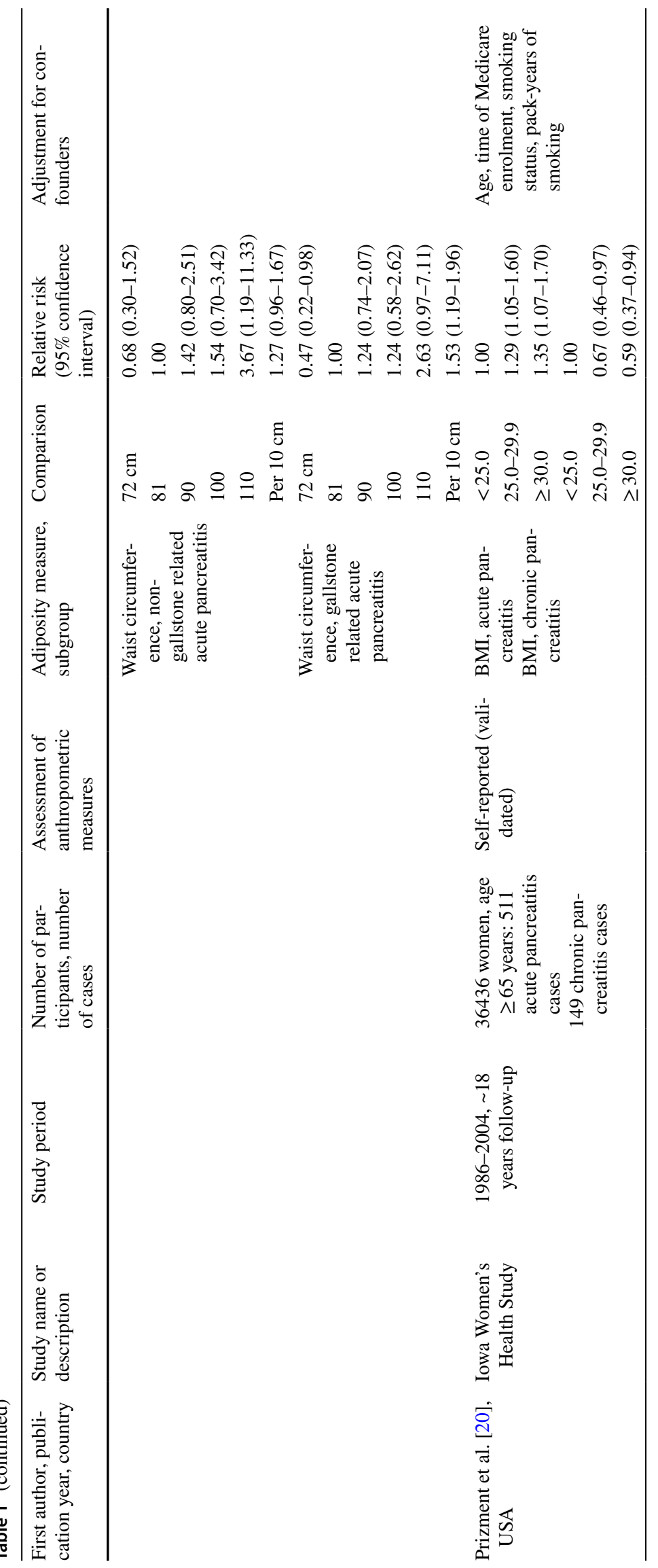




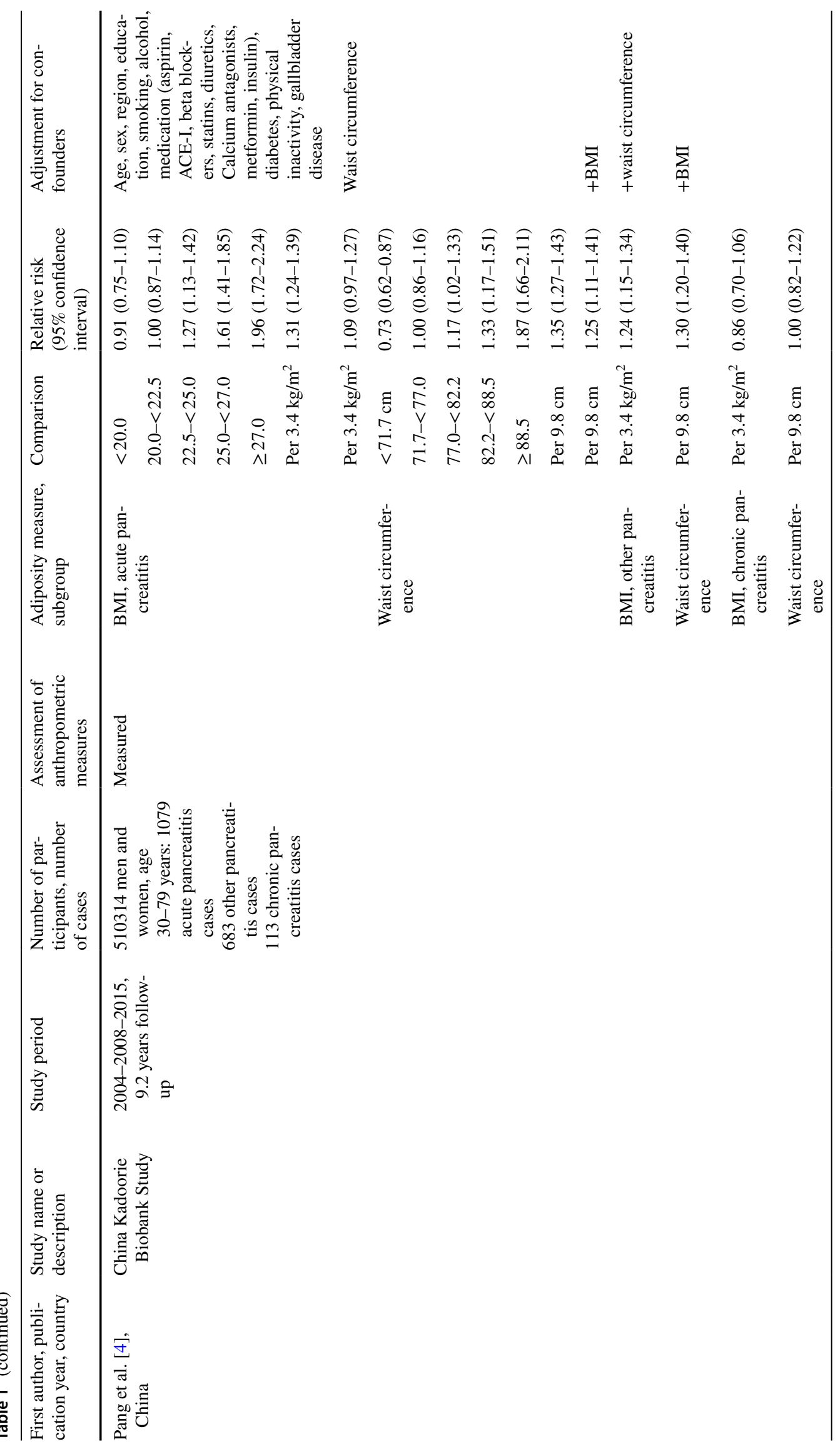




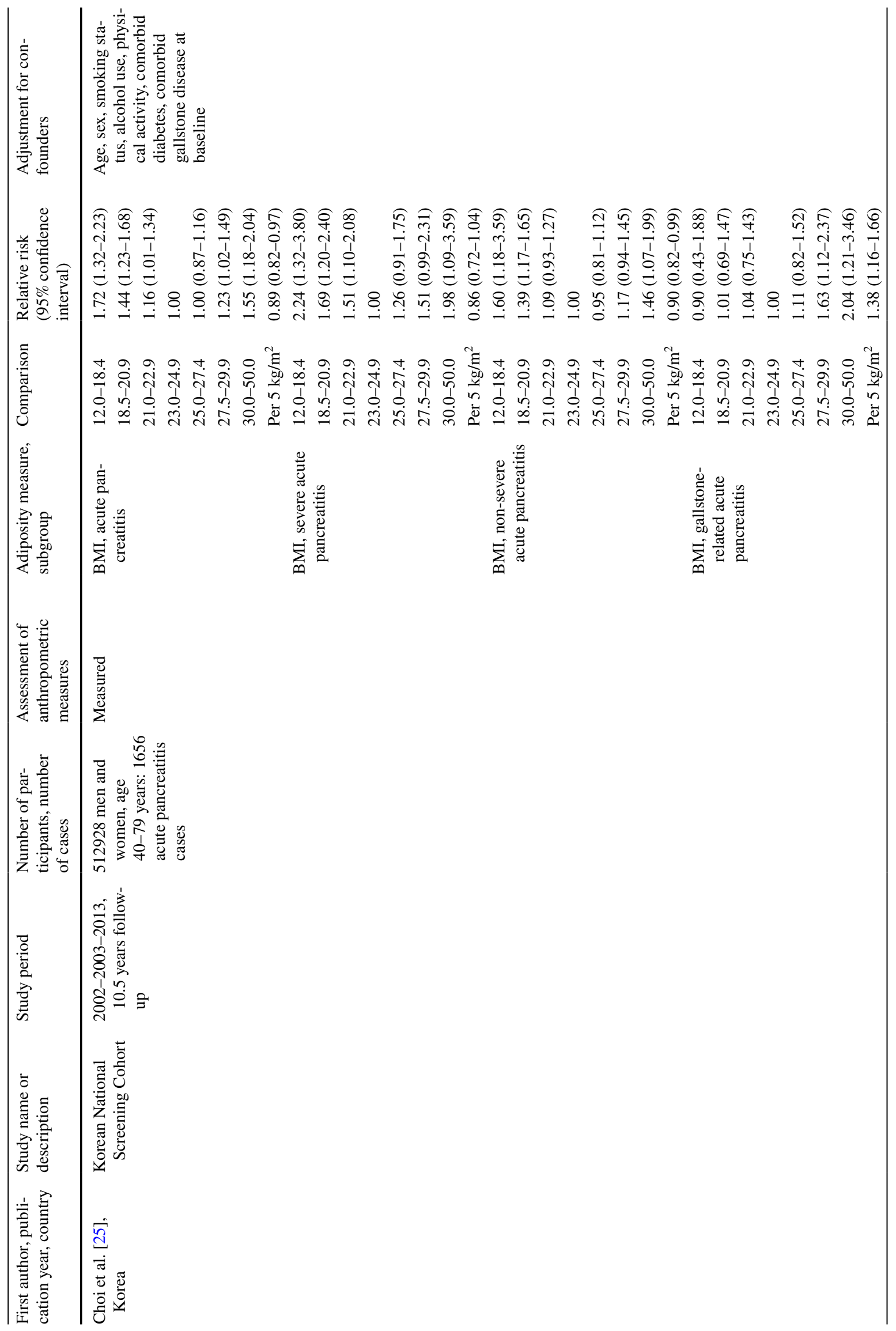




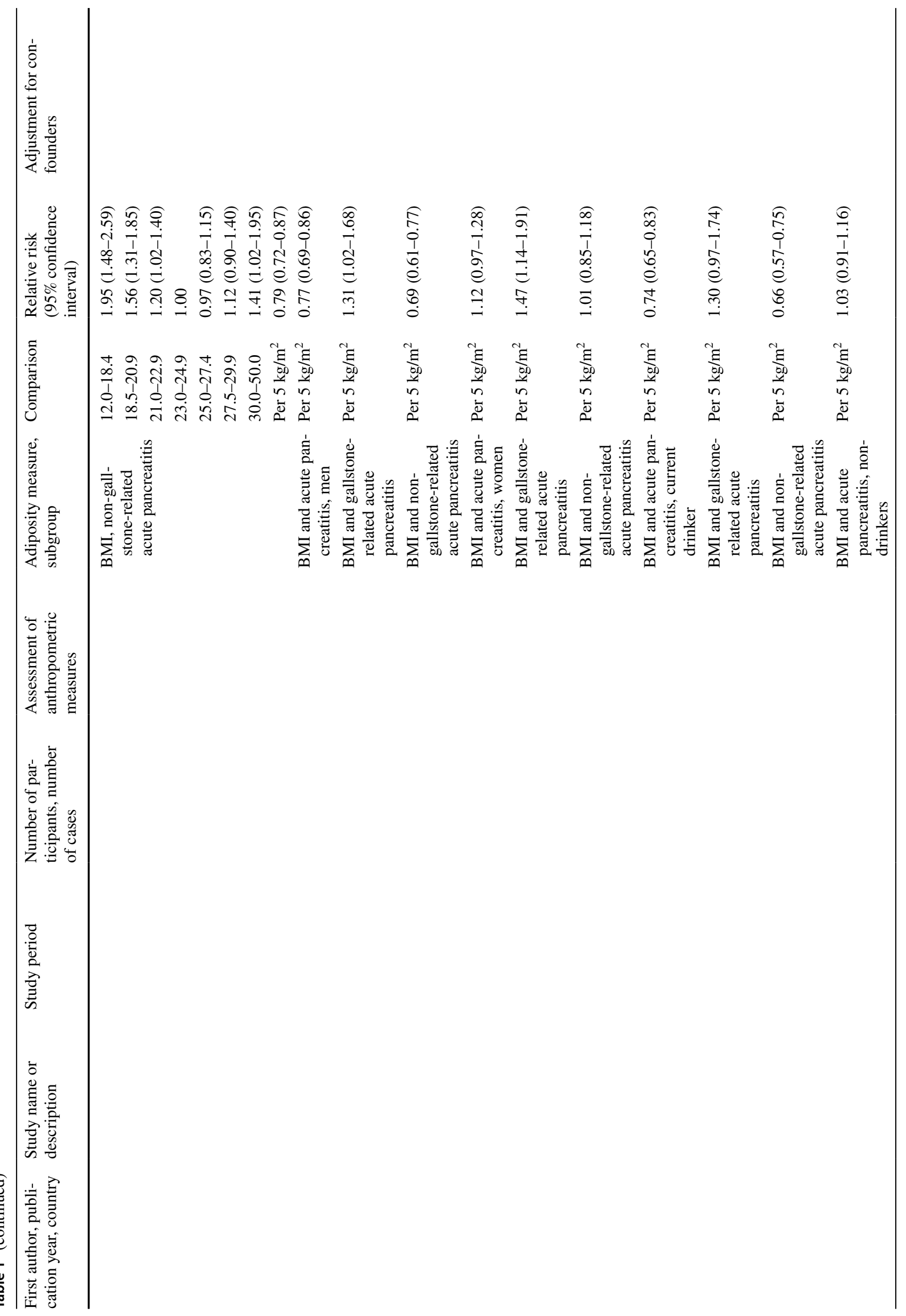




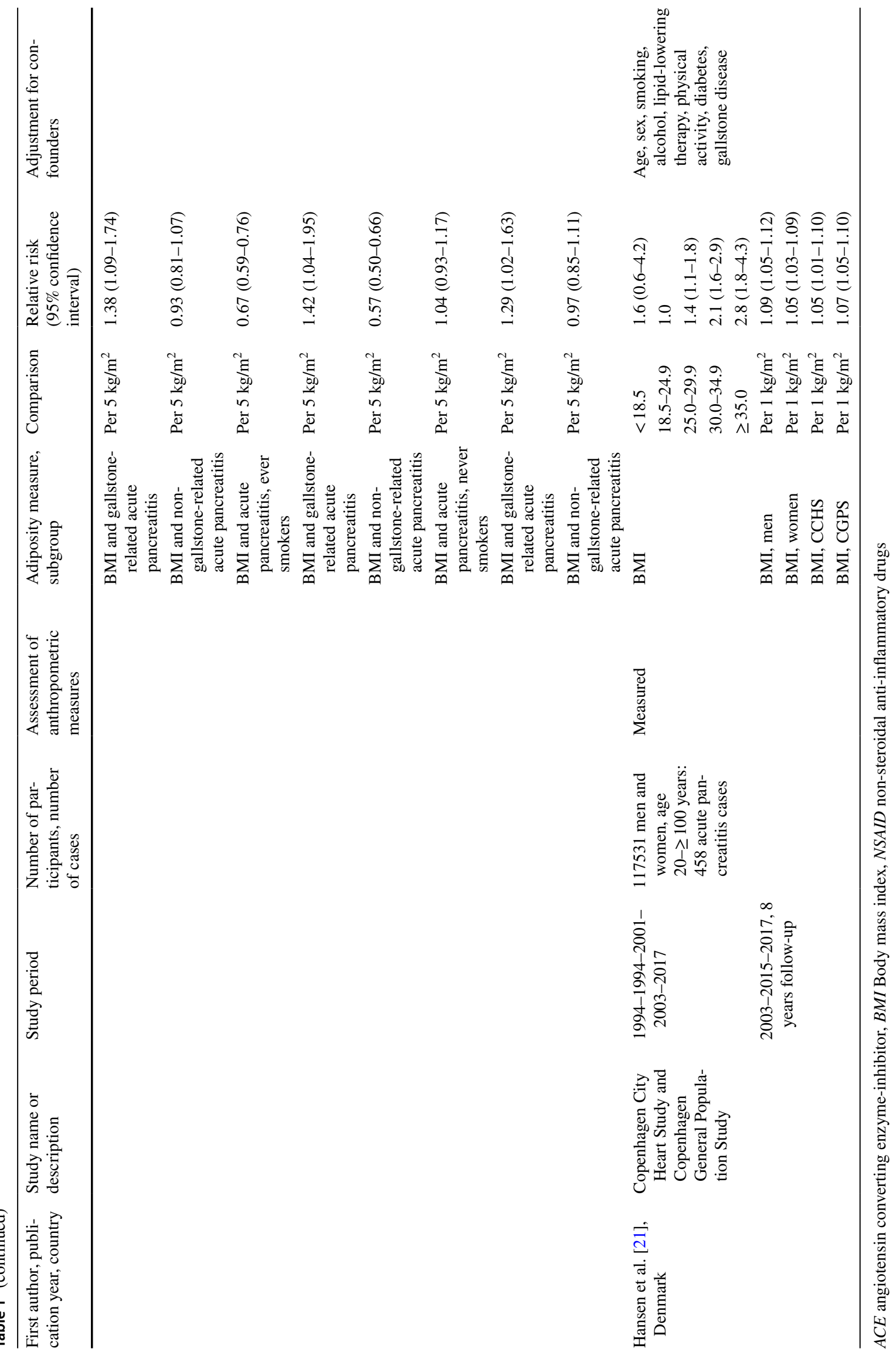


1.25 (95\% CI: $\left.1.12-1.40, I^{2}=85.2 \%, p_{\text {heterogeneity }}<0.0001\right)$ per $5 \mathrm{~kg} / \mathrm{m}^{2}$ increase in BMI (Supplementary Figure 5).

There was evidence of a nonlinear association between BMI and acute pancreatitis $\left(p_{\text {nonlinearity }}<0.0001\right)$, and there was a steeper association at higher levels of BMI than at lower levels (Fig. 2b, Supplementary Table 2). Exclusion of the Korean study led to a more linear dose-response relationship between BMI and acute pancreatitis, although the test for nonlinearity was still significant $\left(p_{\text {nonlinearity }}=0.001\right)$ (Supplementary Figure 3b, Supplementary Table 2).

Only four studies (three publications, three risk estimates) were included in the analysis of BMI and gallstone-related pancreatitis [19, 24, 25] and non-gallstone-related pancreatitis $[19,24,25]$, and two studies were included in the analysis of BMI and chronic pancreatitis [4, 20], and the summary RRs were 1.34 (95\% CI: $1.16-1.56, I^{2}=52 \%, p_{\text {heterogeneity }}=0.13$ ) (Supplementary Figure 6), 0.93 (95\% CI: 0.76-1.14, $I^{2}=82 \%$, $\left.p_{\text {heterogeneity }}=0.004\right)$ (Supplementary Figure 7), and 0.78 (95\% CI: $0.65-0.92, I^{2}=0 \%, p_{\text {heterogeneity }}=0.80$ ) (Supplementary Figure 8), respectively.

Three cohort studies (two publications) [4, 24] were included in the analysis of waist circumference and risk of acute pancreatitis (1503 cases, 578,472 participants). The summary RR was 1.36 (95\% CI: $1.29-1.43, I^{2}=0 \%$, $\left.p_{\text {heterogeneity }}=0.90\right)$ per $10 \mathrm{~cm}$ increase in waist circumference (Fig. 3a). There was no evidence of a nonlinear association between waist circumference and risk of acute pancreatitis $\left(p_{\text {nonlinearity }}=0.19\right)$, and there was a fourfold increase in risk when comparing a waist circumference of $110 \mathrm{~cm}$ with one of $69 \mathrm{~cm}$ (Fig. 3b, Supplementary Table 3).

\section{Subgroup and Sensitivity Analyses}

There was a positive association between BMI and acute pancreatitis in most subgroup analyses stratified by sex, duration of follow-up, number of cases and adjustment for confounding factors (including age, education, alcohol, smoking, waist circumference and physical activity) or potentially mediating factors (diabetes mellitus, gallstones/gallbladder disease and triglycerides), although in some subgroups the association was not statistically significant (Table 2). With meta-regression analyses, there was no evidence that the results differed between these subgroups; however, within-subgroup heterogeneity was lower among studies in women $\left(I^{2}=0 \%\right)$ and among the American studies $\left(I^{2}=0.8 \%\right)$ (Table 2). The mean (median) study quality score was $8.4(8.0)$ out of 9.0.

\section{Discussion}

This meta-analysis of ten prospective studies suggests that a $5 \mathrm{~kg} / \mathrm{m}^{2}$ increase in BMI is associated with an $18 \%$ increase in the relative risk of acute pancreatitis, and a $10 \mathrm{~cm}$ increase in waist circumference is associated with a $36 \%$ increase in the relative risk. There was some evidence of nonlinearity in the analysis of BMI, with a steeper increase in risk at higher levels of BMI than at lower levels and with the increased risk being most pronounced in the obese and severely obese range. When comparing a BMI of 30,35 and 40 with a BMI of 22 , there was a $34 \%, 102 \%$ and $235 \%$ increase in the relative risk of acute pancreatitis. There was no evidence of nonlinearity in the analysis of waist circumference and acute pancreatitis, and there was a fourfold increase in risk when comparing the highest vs. the lowest level of waist circumference. There was a positive association between BMI and gallstone-related pancreatitis, but not with nongallstone-related pancreatitis, while an inverse association was observed between BMI and chronic pancreatitis; however, these results were based on only 2-4 studies; thus, caution is needed in the interpretation of these findings and further studies are needed before firm conclusions can be drawn. Only two studies investigated waist circumference and different types of pancreatitis and found a slightly stronger association with gallstone-related pancreatitis, than for non-gallstone-related pancreatitis [24]; however, there was still a strong and significant association even for the latter. The current findings are consistent with a previous metaanalysis on BMI and acute pancreatitis which found a $43 \%$ increase in the RR among obese compared to normal weight subjects [27]; however, only three studies (two publications) with 603 cases and 101,369 participants were included in the analysis [27], while the current analysis included $>5000$ cases and $>1.69$ million participants and therefore provides a more comprehensive assessment of the available evidence.

Several biological pathways could explain why higher BMI or waist circumference is associated with increased risk of pancreatitis. Excess weight is a strong risk factor for type 2 diabetes [37], gallstones [17] and elevated levels of triglycerides [38], which again are strongly associated with increased risk of pancreatitis [14, 39-42]. The observation in the current analysis that there was a positive association between BMI and gallstone-related pancreatitis, but not for non-gallstone-related pancreatitis $(\mathrm{RR}=1.34$ vs. 0.93 per $5 \mathrm{~kg} / \mathrm{m}^{2}$ ) might suggest that increased risk of gallstones may account for much of the increased risk of pancreatitis with overweight and obesity as measured by BMI; however, given that there were only four studies in each of these analyses, further studies are needed before firm conclusions can be made. In contrast, the association between waist circumference and pancreatitis was strong both for gallstone-related pancreatitis $(R R=2.5)$ and for non-gallstone-related pancreatitis $(R R=2.1)$ in two Swedish cohorts even after adjustment for BMI [24], suggesting that other mechanisms could contribute as well. A combined analysis of two Danish studies suggested recently that elevated triglycerides appeared to mediate $22 \%$ of the excess risk of the association between 
Fig. 2 Body mass index and acute pancreatitis, linear doseresponse analysis per $5 \mathrm{~kg} / \mathrm{m}^{2}$ (a) and nonlinear dose-response analysis (b)
A

Study

Choi, 2019

Hansen, 2019, CCHS

Hansen, 2019, CGPS

Pang, 2018

Prizment, 2015

Sadr-Azodi, 2013

Gonzalez-Perez, 2010

Lindkvist, 2008

Morton, 2004

Overall
Relative Risk

$(95 \% \mathrm{Cl})$

$0.89(0.82,0.97)$

$1.28(1.05,1.61)$

$1.40(1.28,1.61)$

$1.49(1.37,1.62)$

$1.16(1.04,1.29)$

$1.07(0.91,1.25)$

$0.93(0.75,1.15)$

$1.28(1.05,1.54)$

$1.25(1.13,1.38)$

$1.18(1.03,1.35)$

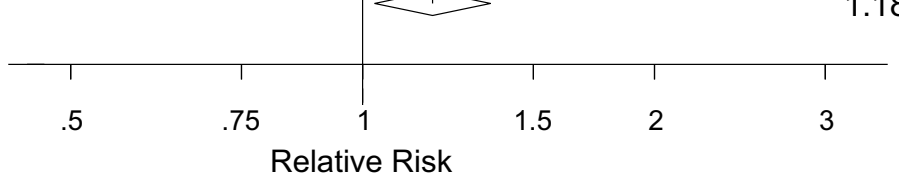

B

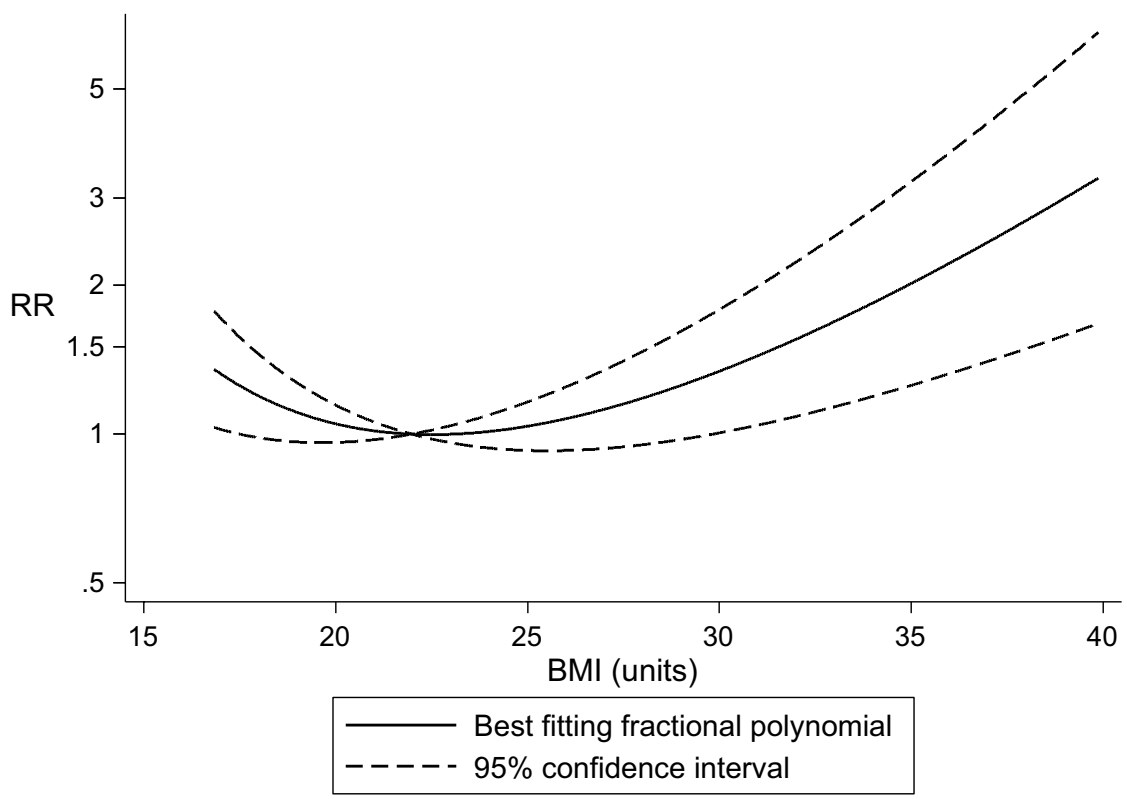

BMI and acute pancreatitis [21]. Higher BMI is associated with more adipocytes within the pancreas which are dispersed adjacent to the exocrine pancreatic acinar cells [43]. In acute pancreatitis, these adipocytes are damaged by the release of lipases which hydrolyze their triglycerides into unsaturated fatty acids, which in turn cause necrosis of the acinar cells [43]. In chronic pancreatitis, adipocyte mass is unrelated to BMI, and adipocytes are surrounded by fibrosis, which prevents the lipolytic flux between the two compartments [43]. This could be part of the explanation for the difference in the results for BMI and acute and chronic pancreatitis. Adiposity could also impact pancreatitis indirectly because certain obesity treatments such as bariatric surgery, duodeno-jejunal bypass liner and gastric balloons in some cases can cause acute pancreatitis; however, this would most likely explain only a small percentage of cases [43]. Adiposity is associated with low-grade inflammation and with lower levels of adiponectin, a cytokine with anti-inflammatory properties and which reduces insulin resistance [44]. It has been shown that adiponectin reduced the development of acute pancreatitis in mice fed a high-fat diet [45].

Limitations that may have affected the results of the current meta-analysis include potential confounding, heterogeneity, measurement errors in the assessment of 
Fig. 3 Waist circumference and acute pancreatitis, linear doseresponse analysis per $10 \mathrm{~cm}(\mathbf{a})$ and nonlinear dose-response analysis (b)
A

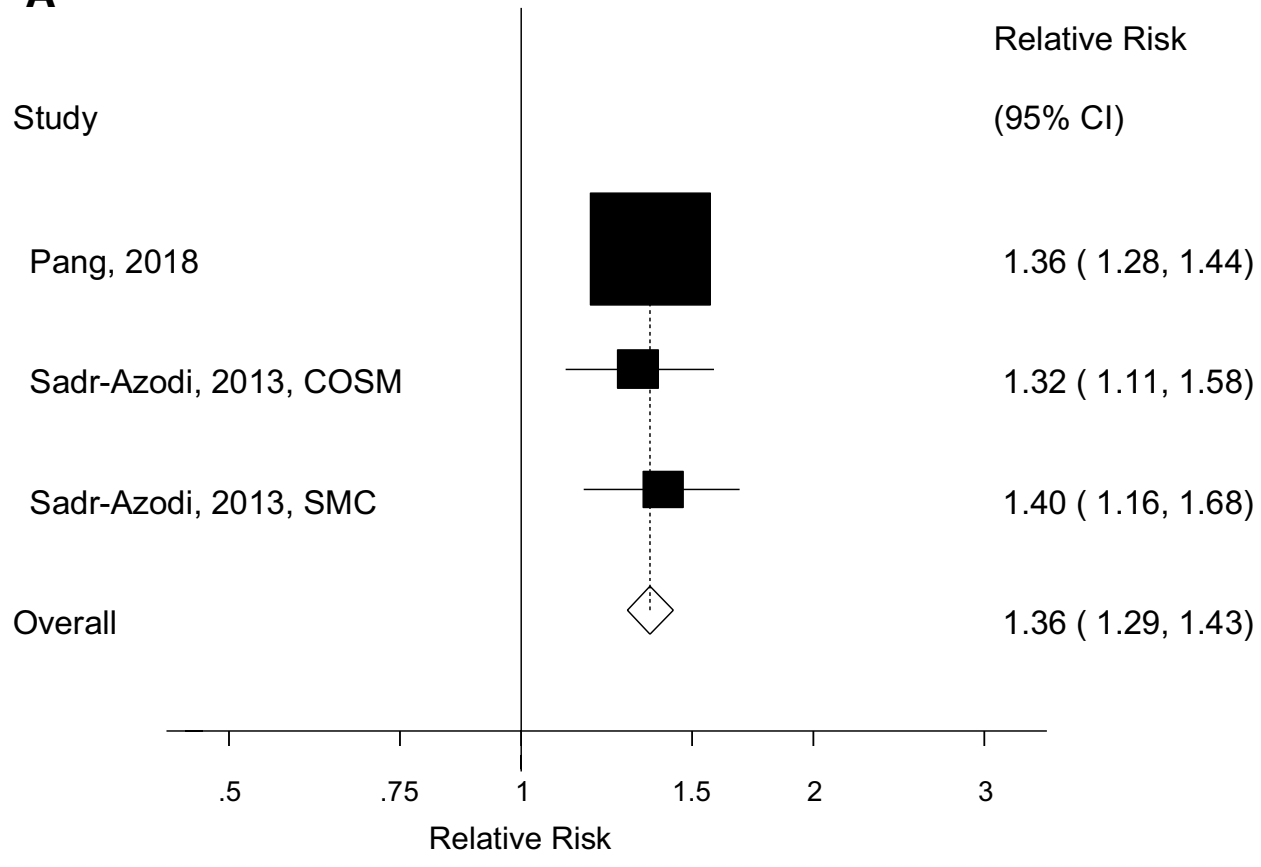

B

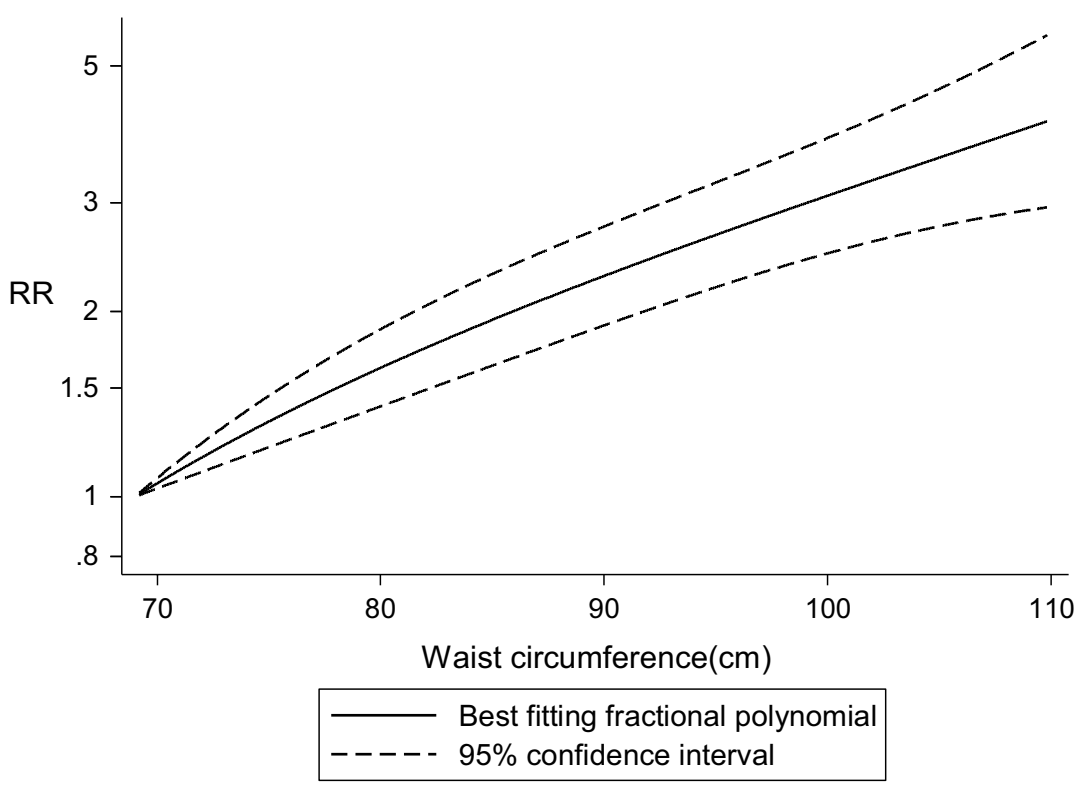

anthropometric measures and publication bias. We cannot exclude the possibility of residual confounding as persons with overweight and obesity tend to have a generally less healthy lifestyle including lower physical activity, unhealthier diets and higher rates of type 2 diabetes compared to normal weight individuals, while persons with a low BMI more often are smokers than persons with a high BMI. Several of the studies adjusted for a range of confounding factors and the results persisted across most subgroups with adjustment for confounding factors. In addition, there was little evidence of heterogeneity between these subgroup analyses. However, one study from Korea suggested an L-shaped or U-shaped association between BMI and acute pancreatitis, with an inverse association overall and among men, ever smokers and alcohol drinkers when the association was analyzed on a continuous scale, but not among women, never smokers and nondrinkers [25]. This might suggest that confounding by smoking and alcohol could have affected the results of that study and is also likely to explain the difference in the association by sex as smoking prevalence is much higher 
Table 2 Subgroup analyses of body mass index and acute pancreatitis

\begin{tabular}{|c|c|c|c|c|c|}
\hline & \multicolumn{5}{|c|}{ Body mass index and acute pancreatitis } \\
\hline & $n$ & Relative risk $(95 \% \mathrm{CI})$ & $I^{2}(\%)$ & $P_{\mathrm{h}}^{1}$ & $P_{\mathrm{h}}^{2}$ \\
\hline All studies & 9 & $1.18(1.03-1.35)$ & 91.1 & $<0.0001$ & \\
\hline \multicolumn{6}{|l|}{ Sex } \\
\hline Men & 2 & $1.09(0.55-2.14)$ & 97.9 & $<0.0001$ & \multirow[t]{3}{*}{$0.60 / 0.75^{3}$} \\
\hline Women & 3 & $1.18(1.09-1.27)$ & 0 & 0.40 & \\
\hline Men, women & 5 & $1.20(1.03-1.41)$ & 84.5 & $<0.0001$ & \\
\hline \multicolumn{6}{|l|}{ Follow-up } \\
\hline$<10$ years & 4 & $1.28(1.09-1.52)$ & 82.0 & 0.001 & \multirow[t]{2}{*}{0.26} \\
\hline$\geq 10$ years & 5 & $1.11(0.96-1.29)$ & 87.7 & $<0.0001$ & \\
\hline \multicolumn{6}{|c|}{ Assessment of weight/height } \\
\hline Measured & 7 & $1.20(1.01-1.43)$ & 93.1 & $<0.0001$ & \multirow[t]{2}{*}{0.63} \\
\hline Self-reported (validated) & 2 & $1.13(1.03-1.23)$ & 0 & 0.41 & \\
\hline \multicolumn{6}{|l|}{ Geographic location } \\
\hline Europe & 5 & $1.19(1.02-1.38)$ & 72.9 & 0.005 & \multirow[t]{3}{*}{0.88} \\
\hline America & 2 & $1.20(1.12-1.30)$ & 0.8 & 0.32 & \\
\hline Asia & 2 & $1.15(0.70-1.90)$ & 98.6 & $<0.0001$ & \\
\hline \multicolumn{6}{|l|}{ Number of cases } \\
\hline Cases $<250$ & 2 & $1.28(1.11-1.47)$ & 0 & 0.99 & \multirow[t]{3}{*}{0.62} \\
\hline Cases $250-<500$ & 4 & $1.17(1.00-1.36)$ & 79.4 & 0.002 & \\
\hline Cases $\geq 500$ & 3 & $1.15(0.84-1.58)$ & 97.2 & $<0.0001$ & \\
\hline \multicolumn{6}{|l|}{ Study quality } \\
\hline $0-3$ stars & 0 & & & & \multirow[t]{3}{*}{$\mathrm{NC}$} \\
\hline 4-6 stars & 0 & & & & \\
\hline $7-9$ stars & 9 & $1.18(1.03-1.35)$ & 91.1 & $<0.0001$ & \\
\hline \multicolumn{6}{|c|}{ Adjustment for confounding factors } \\
\hline \multicolumn{6}{|c|}{ Age } \\
\hline Yes & 9 & $1.18(1.03-1.35)$ & 91.1 & $<0.0001$ & \multirow[t]{2}{*}{$\mathrm{NC}$} \\
\hline No & 0 & & & & \\
\hline \multicolumn{6}{|l|}{ Education } \\
\hline Yes & 3 & $1.27(1.06-1.52)$ & 87.2 & $<0.0001$ & \multirow[t]{2}{*}{0.43} \\
\hline No & 6 & $1.14(0.96-1.35)$ & 89.7 & $<0.0001$ & \\
\hline \multicolumn{6}{|l|}{ Alcohol } \\
\hline Yes & 8 & $1.18(1.01-1.39)$ & 92.2 & $<0.0001$ & \multirow[t]{2}{*}{0.91} \\
\hline No & 1 & $1.16(1.04-1.29)$ & & & \\
\hline \multicolumn{6}{|l|}{ Smoking } \\
\hline Yes & 8 & $1.17(1.00-1.37)$ & 92.1 & $<0.0001$ & 0.76 \\
\hline No & 1 & $1.25(1.13-1.38)$ & & & \\
\hline Waist circumference & & & & & \\
\hline Yes & 1 & $1.07(0.91-1.25)$ & & & 0.59 \\
\hline No & 8 & $1.19(1.03-1.39)$ & 92.0 & $<0.0001$ & \\
\hline Physical activity & & & & & \\
\hline Yes & 4 & $1.24(0.93-1.64)$ & 96.3 & $<0.0001$ & 0.52 \\
\hline No & 5 & $1.15(1.05-1.26)$ & 50.3 & 0.09 & \\
\hline Adjustment for potential $i$ & med & factors & & & \\
\hline Diabetes & & & & & \\
\hline Yes & 6 & $1.16(0.93-1.43)$ & 94.3 & $<0.0001$ & 0.70 \\
\hline No & 3 & $1.21(1.13-1.30)$ & 0 & 0.52 & \\
\hline Gallstones or gallbladder & & & & & \\
\hline Yes & 6 & $1.16(0.93-1.43)$ & 94.3 & $<0.0001$ & 0.70 \\
\hline No & 3 & $1.21(1.13-1.30)$ & 0 & 0.52 & \\
\hline
\end{tabular}


Table 2 (continued)

\begin{tabular}{|c|c|c|c|c|c|}
\hline & \multicolumn{5}{|c|}{ Body mass index and acute pancreatitis } \\
\hline & $n$ & Relative risk $(95 \% \mathrm{CI})$ & $I^{2}(\%)$ & $P_{\mathrm{h}}^{1}$ & $P_{\mathrm{h}}^{2}$ \\
\hline \multicolumn{6}{|c|}{ Triglycerides } \\
\hline Yes & 0 & & & & $\mathrm{NC}$ \\
\hline No & 9 & $1.18(1.03-1.35)$ & 91.1 & $<0.0001$ & \\
\hline \multicolumn{6}{|c|}{$n$ denotes the number of risk estimates (one publication reported the results for two studies combined) } \\
\hline \multicolumn{6}{|c|}{${ }^{1} \mathrm{P}$ for heterogeneity within each subgroup } \\
\hline \multicolumn{6}{|c|}{${ }^{2} \mathrm{P}$ for heterogeneity between subgroups with meta-regression analysis } \\
\hline \multicolumn{6}{|c|}{${ }^{3} \mathrm{P}$ for heterogeneity between men and women, excluding studies of men and women combined } \\
\hline
\end{tabular}

in males than among females in this population [46]. Any further studies could conduct analyses stratified by other risk factors to further explore the impact of residual confounding by smoking and alcohol or other factors. We also cannot exclude residual confounding from non-established risk factors such as diet or other unknown factors. There was high heterogeneity in the overall analysis of BMI and acute pancreatitis; however, heterogeneity was low among studies in women and among the American studies.

There was little differences in the results when subgroups were stratified by adjustment for various confounding factors including alcohol, smoking and physical activity. There was also little heterogeneity between subgroups of studies that adjusted for potential intermediate risk factors including diabetes and gallstones. We can also not exclude the possibility of residual confounding by other potential risk factors, and few studies have adjusted for dietary risk factors to date. However, the confounder would have to be relatively strong to fully account for the threefold-fourfold difference in risk observed for extremes in BMI and waist circumference.

Anthropometry was assessed by self-report in a few studies and this may have led to measurement errors in the exposure assessment; however, this was the case for only three studies which also validated the self-reports. Several studies have shown relatively high correlations between measured and self-reported anthropometric variables with correlation coefficients of around 0.95-0.97, suggesting that self-report of adiposity is relatively accurate [47-49]. Because of the prospective design of the included studies, any measurement errors in the assessment of anthropometric measures would most likely have biased the results toward the null. In addition, the positive associations between BMI and acute pancreatitis persisted both among the seven studies that used measured weight and height for the anthropometric assessment and among the three studies with self-reported weight and height. Although there was no between subgroup heterogeneity the association was slightly stronger in the studies that measured weight and height compared with those that used self-reported anthropometric measures $(\mathrm{RR}=1.20$ vs. 1.13). In the China Kadoorie Biobank Study, more or less similar associations were observed between different adiposity measures such as BMI, waist circumference, waist-to-hip ratio, hip circumference, body fat percentage, height-adjusted weight and weight change and risk of acute pancreatitis [4]. Because anthropometric variables usually were measured only at baseline, it was not possible to take into account changes in adiposity in this analysis and it is therefore possible that weight gain over time may account for part of the association observed between adiposity and the risk of developing pancreatitis. The China Kadoorie Biobank Study found a positive association between both BMI at age 25 and weight change between age 25 and baseline and the risk of acute pancreatitis [4]. Because of limited data on adiposity and severity of pancreatitis, we were not able to analyze this association; however, some previous studies suggested obesity increases the risk of severe pancreatitis, complications and mortality in pancreatitis patients [50-52].

Although publication bias can affect the results of metaanalyses of published studies, we found no evidence of publication bias in the analysis of BMI and acute pancreatitis. There were too few studies to conduct subgroup analyses or test for publication bias in the analysis of waist circumference and acute pancreatitis.

This meta-analysis has several strengths including 1) the prospective design of the included studies which avoids problems with recall bias and reduces the potential for selection bias, 2) the robustness of the findings in multiple subgroup and sensitivity analyses and 3) with $>5,100$ cases and $\sim 1.7$ million participants, we had sufficient statistical power to detect even a moderate association between adiposity and acute pancreatitis. Our findings have important clinical and public health implications as the number of persons who are overweight and obese has increased considerably over the last decades in all areas of the world [53]. If this trend continues it may contribute to additional cases of pancreatitis and related consequences such as increased incidence of pancreatic cancer and premature mortality, but it could be halted with widespread adoption of healthier diets and increased levels of physical activity [54]. 


\section{Conclusion}

This meta-analysis suggests that higher BMI and waist circumference are associated with increased risk of acute pancreatitis. Further studies are needed on different measures of adiposity and the risk of different subtypes of pancreatitis (acute vs. chronic and gallstone-related vs. non-gallstonerelated) and to clarify the underlying mechanisms, but the findings underscore the importance of weight control for the prevention of acute pancreatitis.

Acknowledgments Open Access funding provided by University of Oslo (incl Oslo University Hospital).

Author's contributions DA designed the research, conducted the literature search and analyses and wrote the first draft of the paper. DA and YMS conducted the literature screening. DA, YMS, TN and ER interpreted the data, revised the subsequent drafts for important intellectual content, read and approved the final manuscript. DA takes responsibility for the integrity of the data and the accuracy of the data analysis.

Funding This work was funded by the Imperial College School of Public Health and the South-East Regional Health Authority of Norway.

\section{Compliance with ethical standards}

Conflict of interest The authors declare that there is no duality of interest associated with this manuscript.

Open Access This article is licensed under a Creative Commons Attribution-NonCommercial 4.0 International License, which permits any non-commercial use, sharing, adaptation, distribution and reproduction in any medium or format, as long as you give appropriate credit to the original author(s) and the source, provide a link to the Creative Commons licence, and indicate if changes were made. The images or other third party material in this article are included in the article's Creative Commons licence, unless indicated otherwise in a credit line to the material. If material is not included in the article's Creative Commons licence and your intended use is not permitted by statutory regulation or exceeds the permitted use, you will need to obtain permission directly from the copyright holder.To view a copy of this licence, visit http://creativecommons.org/licenses/by-nc/4.0/.

\section{References}

1. Hammad AY, Ditillo M, Castanon L. Pancreatitis. Surg Clin North Am. 2018;98:895-913.

2. Muniraj T, Aslanian HR, Farrell J, Jamidar PA. Chronic pancreatitis, a comprehensive review and update. Part I: Epidemiology, etiology, risk factors, genetics, pathophysiology, and clinical features. Dis Mon. 2014;60:530-550.

3. Kirkegard J, Mortensen FV, Cronin-Fenton D. Chronic pancreatitis and pancreatic cancer risk: a systematic review and metaanalysis. Am J Gastroenterol. 2017;112:1366-1372.

4. Pang Y, Kartsonaki C, Turnbull I, et al. Metabolic and lifestyle risk factors for acute pancreatitis in Chinese adults: a prospective cohort study of 0.5 million people. PLoS Med. 2018;15:e1002618.

5. Bang UC, Benfield T, Hyldstrup L, Bendtsen F, Beck Jensen JE. Mortality, cancer, and comorbidities associated with chronic pancreatitis: a Danish nationwide matched-cohort study. Gastroenterology. 2014;146:989-994.

6. Xiao AY, Tan ML, Wu LM, et al. Global incidence and mortality of pancreatic diseases: a systematic review, meta-analysis, and meta-regression of population-based cohort studies. Lancet Gastroenterol Hepatol. 2016;1:45-55.

7. McKay CJ, Evans S, Sinclair M, Carter CR, Imrie CW. High early mortality rate from acute pancreatitis in Scotland, 19841995. Br J Surg. 1999;86:1302-1305.

8. Kingsnorth A, O'Reilly D. Acute pancreatitis. BMJ. 2006;332:1072-1076.

9. Jaakkola M, Nordback I. Pancreatitis in Finland between 1970 and 1989. Gut. 1993;34:1255-1260.

10. Spanier BW, Dijkgraaf MG, Bruno MJ. Trends and forecasts of hospital admissions for acute and chronic pancreatitis in the Netherlands. Eur J Gastroenterol Hepatol. 2008;20:653-658.

11. Tinto A, Lloyd DA, Kang JY, et al. Acute and chronic pancreatitis-diseases on the rise: a study of hospital admissions in England 1989/90-1999/2000. Aliment Pharmacol Ther. 2002;16:2097-2105.

12. Fagenholz PJ, Castillo CF, Harris NS, Pelletier AJ, Camargo CA Jr. Increasing United States hospital admissions for acute pancreatitis, 1988-2003. Ann Epidemiol. 2007;17:491-497.

13. Roberts SE, Morrison-Rees S, John A, Williams JG, Brown TH, Samuel DG. The incidence and aetiology of acute pancreatitis across Europe. Pancreatology. 2017;17:155-165.

14. Lin HH, Chang HY, Chiang YT, Wu MS, Lin JT, Liao WC. Smoking, drinking, and pancreatitis: a population-based cohort study in Taiwan. Pancreas. 2014;43:1117-1122.

15. Majumder S, Gierisch JM, Bastian LA. The association of smoking and acute pancreatitis: a systematic review and metaanalysis. Pancreas. 2015;44:540-546.

16. Abdullah A, Peeters A, de Court, Stoelwinder J. The magnitude of association between overweight and obesity and the risk of diabetes: a meta-analysis of prospective cohort studies. Diabetes Res Clin Pract. 2010;89:309-319.

17. Aune D, Norat T, Vatten LJ. Body mass index, abdominal fatness and the risk of gallbladder disease. Eur J Epidemiol. 2015;30:1009-1019.

18. Aune D, Greenwood DC, Chan DS, et al. Body mass index, abdominal fatness and pancreatic cancer risk: a systematic review and non-linear dose-response meta-analysis of prospective studies. Ann Oncol. 2012;23:843-852.

19. Morton C, Klatsky AL, Udaltsova N. Smoking, coffee, and pancreatitis. Am J Gastroenterol. 2004;99:731-738.

20. Prizment AE, Jensen EH, Hopper AM, Virnig BA, Anderson KE. Risk factors for pancreatitis in older women: the Iowa Women's Health Study. Ann Epidemiol. 2015;25:544-548.

21. Hansen SEJ, Madsen CM, Varbo A, Nordestgaard BG. Body mass index, triglycerides, and risk of acute pancreatitis: a population-based study of 118,000 individuals. J Clin Endocrinol Metab. 2020;105:2020.

22. Lindkvist B, Appelros S, Manjer J, Berglund G, Borgstrom A. A prospective cohort study of smoking in acute pancreatitis. Pancreatology. 2008;8:63-70.

23. Gonzalez-Perez A, Schlienger RG, Rodriguez LA. Acute pancreatitis in association with type 2 diabetes and antidiabetic drugs: a population-based cohort study. Diabetes Care. 2010;33:2580-2585.

24. Sadr-Azodi O, Orsini N, Andren-Sandberg A, Wolk A. Abdominal and total adiposity and the risk of acute pancreatitis: a population-based prospective cohort study. Am J Gastroenterol. 2013;108:133-139.

25. Choi JS, Yi SW, Park JW, et al. Body mass index and the risk of acute pancreatitis by etiology: a prospective analysis of 
Korean National Screening Cohort. J Gastroenterol Hepatol. 2019;34:603-611.

26. Hong S, Qiwen B, Ying J, Wei A, Chaoyang T. Body mass index and the risk and prognosis of acute pancreatitis: a meta-analysis. Eur J Gastroenterol Hepatol. 2011;23:1136-1143.

27. Alsamarrai A, Das SL, Windsor JA, Petrov MS. Factors that affect risk for pancreatic disease in the general population: a systematic review and meta-analysis of prospective cohort studies. Clin Gastroenterol Hepatol. 2014;12:1635-1644.

28. Moher D, Liberati A, Tetzlaff J, Altman DG. Preferred reporting items for systematic reviews and meta-analyses: the PRISMA statement. BMJ. 2009;339:b2535.

29. DerSimonian R, Laird N. Meta-analysis in clinical trials. Control Clin Trials. 1986;7:177-188.

30. Greenland S, Longnecker MP. Methods for trend estimation from summarized dose-response data, with applications to meta-analysis. Am J Epidemiol. 1992;135:1301-1309.

31. Bagnardi V, Zambon A, Quatto P, Corrao G. Flexible metaregression functions for modeling aggregate dose-response data, with an application to alcohol and mortality. Am J Epidemiol. 2004;159:1077-1086.

32. Royston P. A strategy for modelling the effect of a continuous covariate in medicine and epidemiology. Stat Med. 2000;19:1831-1847.

33. Higgins JP, Thompson SG. Quantifying heterogeneity in a metaanalysis. Stat Med. 2002;21:1539-1558.

34. Wells G, Shea B, O'Connell D., Peterson J, Welch V, Losos M, Tugwell P. The Newcastle-Ottawa Scale (NOS) for assessing the quality of nonrandomised studies in meta-analyses. http://www. ohri.ca/programs/clinical_epidemiology/oxford.asp. Accessed 09.08.2018.

35. Egger M, Davey SG, Schneider M, Minder C. Bias in meta-analysis detected by a simple, graphical test. BMJ. 1997;315:629-634.

36. Begg CB, Mazumdar M. Operating characteristics of a rank correlation test for publication bias. Biometrics. 1994;50:1088-1101.

37. Langenberg C, Sharp SJ, Schulze MB, et al. Long-term risk of incident type 2 diabetes and measures of overall and regional obesity: the EPIC-InterAct case-cohort study. PLoS Med. 2012;9:e1001230.

38. Bays HE, Toth PP, Kris-Etherton PM, et al. Obesity, adiposity, and dyslipidemia: a consensus statement from the National Lipid Association. J Clin Lipidol. 2013;7:304-383.

39. Girman CJ, Kou TD, Cai B, et al. Patients with type 2 diabetes mellitus have higher risk for acute pancreatitis compared with those without diabetes. Diabetes Obes Metab. 2010;12:766-771.

40. Garg R, Chen W, Pendergrass M. Acute pancreatitis in type 2 diabetes treated with exenatide or sitagliptin: a retrospective observational pharmacy claims analysis. Diabetes Care. 2010;33:2349-2354.
41. Urushihara $\mathrm{H}$, Taketsuna $\mathrm{M}$, Liu $\mathrm{Y}$, et al. Increased risk of acute pancreatitis in patients with type 2 diabetes: an observational study using a Japanese hospital database. PLoS One. 2012;7:e53224.

42. Pedersen SB, Langsted A, Nordestgaard BG. Nonfasting mildto-moderate hypertriglyceridemia and risk of acute pancreatitis. JAMA Intern Med. 2016;176:1834-1842.

43. Khatua B, El-Kurdi B, Singh VP. Obesity and pancreatitis. Curr Opin Gastroenterol. 2017;33:374-382.

44. Matsuzawa Y. Adiponectin: a key player in obesity related disorders. Curr Pharm Des. 2010;16:1896-1901.

45. Araki H, Nishihara T, Matsuda M, et al. Adiponectin plays a protective role in caerulein-induced acute pancreatitis in mice fed a high-fat diet. Gut. 2008;57:1431-1440.

46. Jee SH, Samet JM, Ohrr H, Kim JH, Kim IS. Smoking and cancer risk in Korean men and women. Cancer Causes Control. 2004;15:341-348.

47. Spencer EA, Appleby PN, Davey GK, Key TJ. Validity of selfreported height and weight in 4808 EPIC-Oxford participants. Public Health Nutr. 2002;5:561-565.

48. Bes-Rastrollo M, Sabate J, Jaceldo-Siegl K, Fraser GE. Validation of self-reported anthropometrics in the Adventist Health Study 2. BMC Public Health. 2011;11:213.

49. Lee DH, Shin A, Kim J, Yoo KY, Sung J. Validity of selfreported height and weight in a Korean population. J Epidemiol. 2011;21:30-36.

50. Papachristou GI, Papachristou DJ, Avula H, Slivka A, Whitcomb DC. Obesity increases the severity of acute pancreatitis: performance of APACHE-O score and correlation with the inflammatory response. Pancreatology. 2006;6:279-285.

51. Chen SM, Xiong GS, Wu SM. Is obesity an indicator of complications and mortality in acute pancreatitis? An updated metaanalysis. J Dig Dis. 2012;13:244-251.

52. Dobszai D, Matrai P, Gyongyi Z, et al. Body-mass index correlates with severity and mortality in acute pancreatitis: a meta-analysis. World J Gastroenterol. 2019;25:729-743.

53. NCD Risk Factor Collaboration (NCD-RisC). Worldwide trends in body-mass index, underweight, overweight, and obesity from 1975 to 2016: a pooled analysis of 2416 population-based measurement studies in 128.9 million children, adolescents, and adults. Lancet. 2017;390:2627-2642.

54. Mozaffarian D, Hao T, Rimm EB, Willett WC, Hu FB. Changes in diet and lifestyle and long-term weight gain in women and men. N Engl J Med. 2011;364:2392-2404.

Publisher's Note Springer Nature remains neutral with regard to jurisdictional claims in published maps and institutional affiliations. 